\title{
Sensitive Analysis for the Efficiency of a Parabolic Trough Solar Collector Based on Orthogonal Experiment
}

\author{
Xiaoyan Liu, ${ }^{1,2}$ Jing Huang, ${ }^{3}$ and Qianjun Mao ${ }^{1}$ \\ ${ }^{1}$ School of Civil Engineering, Northeast Petroleum University, Daqing 163318, China \\ ${ }^{2}$ The Higher Educational Key Laboratory for Disaster Prevention, Mitigation and Protection Engineering of Heilongjiang Province, \\ Northeast Petroleum University, Daqing 163318, China \\ ${ }^{3}$ Installation Company, Daqing Oilfield Construction Company Ltd., Daqing 163300, China
}

Correspondence should be addressed to Xiaoyan Liu; liu_xydq@163.com and Qianjun Mao; maoqianjun@163.com

Received 10 July 2015; Accepted 24 August 2015

Academic Editor: Xudong Zhao

Copyright (C) 2015 Xiaoyan Liu et al. This is an open access article distributed under the Creative Commons Attribution License, which permits unrestricted use, distribution, and reproduction in any medium, provided the original work is properly cited.

A multitude of the researches focus on the factors of the thermal efficiency of a parabolic trough solar collector, that is, the opticalthermal efficiency. However, it is limited to a single or double factors for available system. The aim of this paper is to investigate the multifactors effect on the system's efficiency in cold climate region. Taking climatic performance into account, an average outlet temperature of LS-2 collector has been simulated successfully by coupling SolTrace software with CFD software. Effects of different factors on instantaneous efficiency have been determined by orthogonal experiment and single factor experiment. After that, the influence degree of different factors on the collector instantaneous efficiency is obtained clearly. The results show that the order of effect extent for average maximal deviation of each factor is inlet temperature, solar radiation intensity, diameter, flow rate, condensation area, pipe length, and ambient temperature. The encouraging results will provide a reference for the exploitation and utilization of parabolic trough solar collector in cold climate region.

\section{Introduction}

Recently, with the increasing attention of the international community about energy problem, solar energy and the other renewable energies rise gradually on large-scale application [1]. Under this background, the solar energy converting technology, especially concentrating light technology, has a broad prospect. There are several common concentrating collectors, such as trough type, dish type, and tower type. Compared with the other two collectors, the trough solar energy collector has been widely used. The most mature technologies are its convenient installation, simple construction, and the low cost [2-4]. Based on the above characteristics, a multitude of the researches focus on the factors of the thermal efficiency of a parabolic trough collector from a view of the optical and thermal properties.

Gao et al. $[5,6]$ have carried out the simulation on the performance of parabolic trough solar collector according to $30 \mathrm{~m}^{2}$ experimental devices. The relationship of efficiency with the solar flux, the heat transfer fluid flow rate, the wind speed, and the diameter of the receivers has been found. Lüpfert et al. [7] have proposed methods for measuring receiver heat losses including field measurement and laboratory setups both based on energy balances from the hot inside of the receiver tube to the ambient air. Zhang et al. $[8,9]$ have presented an experimental study of the heat losses of a double glazing vacuum U-type solar receiver mounted in a parabolic trough collector natural circulation system for generating medium-temperature steam. Kalogirou [10] has a survey of the various types of solar thermal collector and application. The results of the paper show that solar energy collectors can be used in a wide variety of systems, can provide significant environmental and financial benefits, and will be used whenever possible. Xiao et al. [11] have simulated the heat flux distribution on the outer surface of absorber tube of a parabolic solar collector receiver based on Monte Carlo Ray-Trace method. Nonlinear heat flux distribution was considered as complex boundary condition used in FVM to simulate the coupled heat transfer problem. The results show that the angle span of reducing area becomes larger 
TABLE 1: The basic parameters of the LS-2 collector.

\begin{tabular}{lcccc}
\hline Pipe length $(\mathrm{m})$ & Opening width $(\mathrm{m})$ & Focal length $(\mathrm{m})$ & Metal tube diameter $(\mathrm{m})$ & Glass tube diameter $(\mathrm{m})$ \\
\hline 7.8 & 5 & 1.49 & 0.067 (inner) $/ 0.075$ (outer) & 0.115 \\
\hline
\end{tabular}

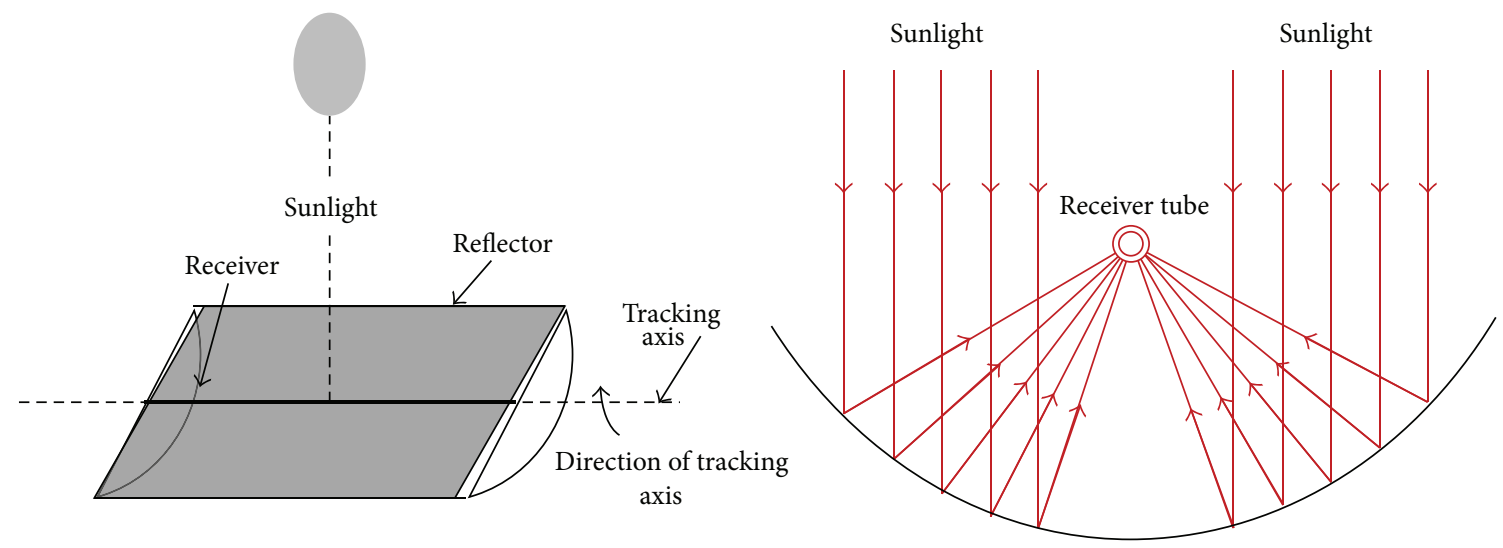

FIgURE 1: The main view and the axial diagram of the collector.

with increasing geometric concentration ratios. Naeeni and Yaghoubi [12] have investigated a two-dimensional numerical simulation of turbulent flow around parabolic tough collectors of the $250 \mathrm{~kW}$ solar power plants in Shiraz, Iran.

It is important to study the parabolic trough solar collector according to the above literature summaries. However, it is limited to single or double factors for available system. The aim of this paper is to investigate the multifactors effect on the system's efficiency in cold climate region. Therefore, effects of different factors on instantaneous efficiency have been determined by orthogonal experiment and simulated for each group of experiments. After that, the influence degree of different factors on the collector instantaneous efficiency is obtained clearly.

\section{Model}

2.1. Physical Model. In order to analyze the efficiency conveniently, LS-2 experiment trough solar collector has been selected for this study designed by Dudley et al. [13]. The basic parameters of the collector are listed in Table 1 . The main view and axial diagram of the collector are shown in Figure 1.

The main principles of the model shown in Figure 1 are the following: the incident sunlights on the earth's surface deriving from the sun through the atmosphere hit the parabolic trough reflector and remain as perpendicular to the incident angle as possible through the solar tracking device; then the energy received by the reflector is reflected to the receiver. Therefore the receiver has received the high heat flux density of solar radiation, and the working fluid inside the pipe is heated to provide thermal power for the electric production.

2.2. Mathematical Model. The calculation of wall heat flux in collector's tube is numerically simulated using SolTrace software. Simulation conditions are as follows: the collector of the reflector plate is selected to aluminum with the reflectivity of 0.76 , refractive index of 1 , shape error of $3 \mathrm{mrad}$, and specular reflection error of $0.5 \mathrm{mrad}$; also, the reflectivity of metal collector tube is of 0.1 , refractive index of 0 , shape error of $0.0001 \mathrm{mrad}$, and specular reflection error of $0.0001 \mathrm{mrad}$. It is simulated by the ray-tracing method after the optical geometric parameters have been set. It is shown that the calculation accuracy is higher and the degree of operation is less when the ray quantities are $10^{6}$ and the most inputting lights are $10^{8}$. According to the simulated heat flux, the optical efficiency is calculated as follows:

$$
\eta_{\mathrm{opt}}=\frac{q_{u} \pi D_{2} L}{I A_{m}}
$$

The instantaneous efficiency of the collector can be calculated by CFD software. The model of receiver tube and the $2 \mathrm{D}$ mesh has been obtained by Gambit tool. The division of grid adopts tetrahedral mesh; the grid size of fluid part is $1 \mathrm{~mm}$, the grid size of the metal part is $2 \mathrm{~mm}$, and grid needs to refine for both inner and outer surface of metal wall. The boundary condition of inlet section is velocity inlet whereas it is pressure outlet for the outlet. According to the simulation results, the instantaneous efficiency is calculated as follows:

$$
\eta=\frac{Q_{u}}{A_{m} I}=\frac{C_{p} m\left(t_{\text {out }}-t_{\text {in }}\right)}{A_{m} I}
$$

where $\eta_{\text {opt }}$ is the optical efficiency of collector; $A_{m}$ is the opening area of parabolic mirror, $\mathrm{m}^{2} ; I$ is solar radiation intensity, $\mathrm{W} / \mathrm{m}^{2} ; Q_{u}$ is the available energy of working fluid in the heating metal tube, $\mathrm{W} ; q_{u}$ is the surface heat flux of receiver, $\mathrm{W} / \mathrm{m}^{2} ; D_{2}$ is the external diameter of receiver tube, $\mathrm{mm}$; $L$ is the length of vacuum tube, $\mathrm{m} ; t_{\mathrm{in}}$ is the temperature 

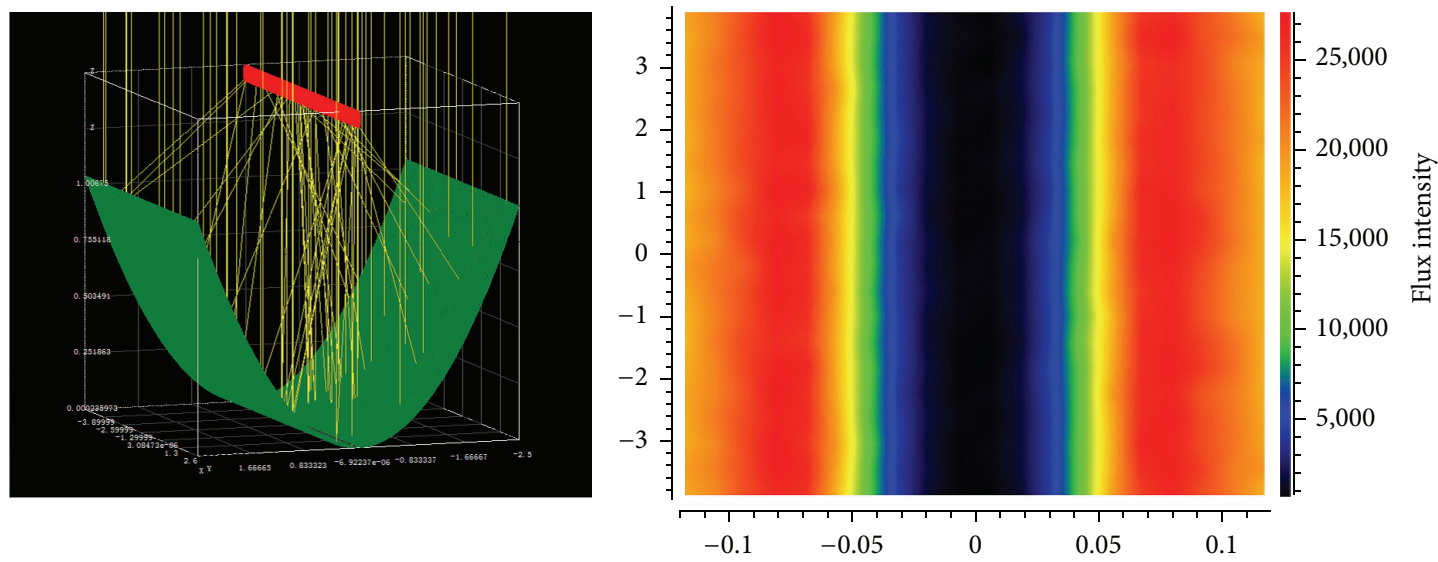

FIgURE 2: The simulation model and the heat density distribution of the LS-2 collector.
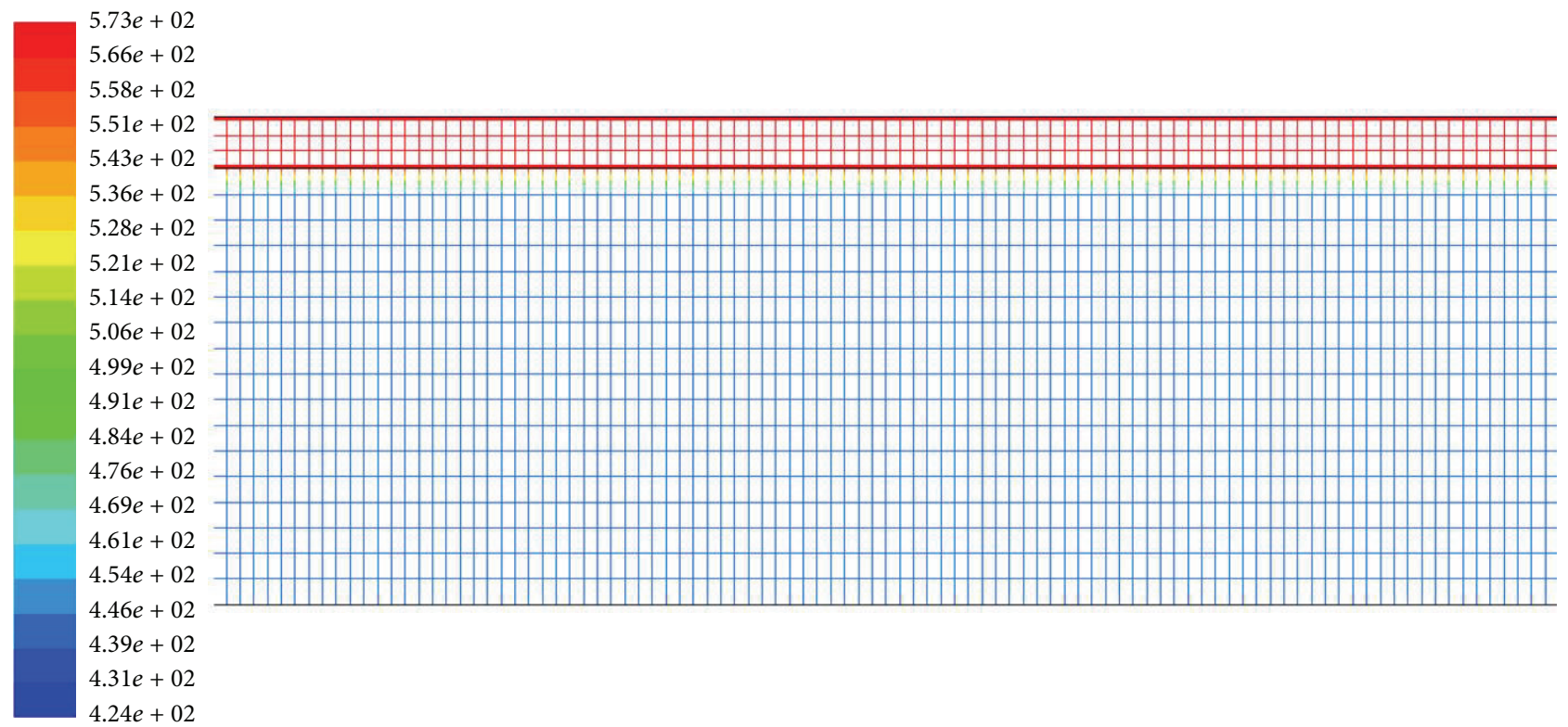

Figure 3: The temperature cloud of the receiver tube.

of fluid inlet, ${ }^{\circ} \mathrm{C}$; $t_{\text {out }}$ is the average temperature of fluid outlet, ${ }^{\circ} \mathrm{C} ; m$ is the mass flow of fluid, $\mathrm{kg} / \mathrm{s} . \mathrm{C}_{p}$ is specific heat $\mathrm{J} /(\mathrm{kg} \cdot \mathrm{K})$.

\section{Results and Discussions}

\subsection{Verification of Simulation Results}

3.1.1. Model Validation of Optical Efficiency. Simulation model and heat density distribution with the direct normal irradiance of $968.2 \mathrm{~W} / \mathrm{m}^{2}$ were shown in Figure 2. According to 1-50 rays, the result of average heat flux density of the collector is $15306 \mathrm{~W} / \mathrm{m}^{2}$. After that, the optical efficiency of $74.5 \%$ can be obtained by (1). Reference [13] shows that experimental results of the optical efficiency are $73.7 \%$. Therefore, there is a good agreement of $1.07 \%$ between the simulation and experiment results.
3.1.2. Model Validation of Instantaneous Efficiency. To obtain the average outer temperature and the efficiency, the concrete parameter conditions are as follows: wind speed is $3.7 \mathrm{~m} / \mathrm{s}$, the ambient temperature is $22.4^{\circ} \mathrm{C}$, the inlet flow rate is $0.24 \mathrm{~m} / \mathrm{s}$, and the inlet temperature of collector is $151^{\circ} \mathrm{C}$. According to the average heat flux of metal tube surface simulated by SolTrace software, the average temperature of the fluid outlet has been simulated with the second boundary condition. Figure 3 shows the temperature cloud picture of the receiver tube. By monitoring on the average temperature of outlet, it is found that the temperature is $170.3^{\circ} \mathrm{C}$ when the iteration has been converged, which has an error of $0.4 \%$ with the previous experiment results of $171.3^{\circ} \mathrm{C}$ [13]. The instantaneous efficiency of collector is $62.2 \%$.

3.2. Sensitive Analysis of a Parabolic Trough Collector in Cold Climate. It can be seen from the above section that the model is correct. In this section, water is used as the heat transfer 
TABLE 2: The factors and levels graph.

\begin{tabular}{cccccccc}
\hline Level & $\begin{array}{c}\text { Pipe length } \\
(\mathrm{m})\end{array}$ & $\begin{array}{c}\text { Condensation } \\
\text { area } \\
(\mathrm{m})\end{array}$ & $\begin{array}{c}\text { Fiameter } \\
(\mathrm{mm})\end{array}$ & $\begin{array}{c}\text { Solar radiation } \\
\text { intensity } \\
\left(\mathrm{W} / \mathrm{m}^{2}\right)\end{array}$ & $\begin{array}{c}\text { Ambient } \\
\text { temperature } \\
\left({ }^{\circ} \mathrm{C}\right)\end{array}$ & $\begin{array}{c}\text { Flow rate } \\
(\mathrm{m} / \mathrm{s})\end{array}$ & $\begin{array}{c}\text { Inlet } \\
\text { temperature } \\
\left({ }^{\circ} \mathrm{C}\right)\end{array}$ \\
\hline 1 & 0.1 & 2 & 55 & 200 & -20 & 0.1 & 30 \\
2 & 2 & 4.5 & 70 & 600 & 0 & 0.2 & 150 \\
3 & 7 & 6.5 & 100 & 800 & 20 & 0.3 \\
\hline
\end{tabular}

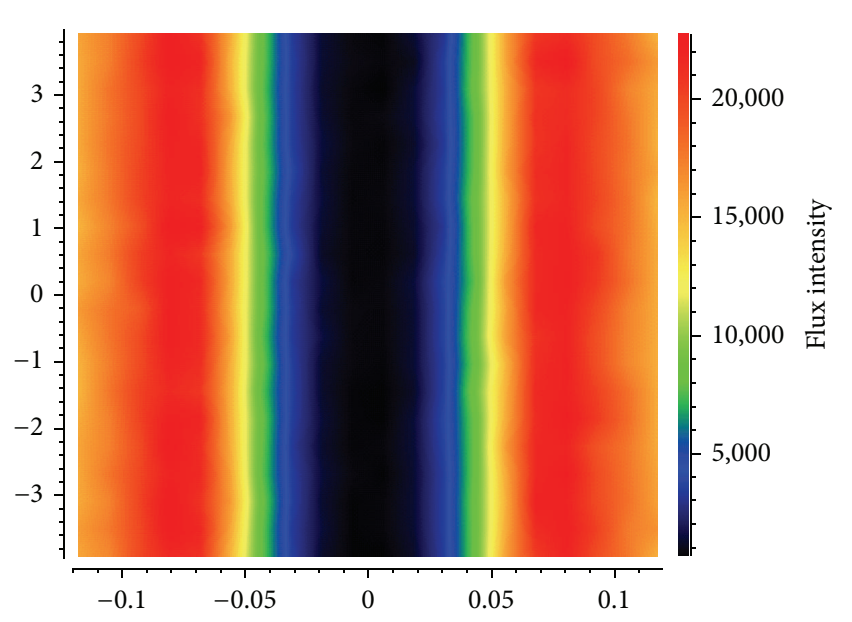

FIgURE 4: The heat density distribution of the collector.

medium and ambient parameters of the coldest month in Daqing city are regarded as meteorological parameters. The main parameters are the following: fluid inlet temperature is $30^{\circ} \mathrm{C}$, flow rate is $0.2 \mathrm{~m} / \mathrm{s}$, solar radiation intensity is $800 \mathrm{~W} / \mathrm{m}^{2}$, and the ambient temperature is $-18.5^{\circ} \mathrm{C}$. Firstly, the average heat flux density of receiver is $12884.4 \mathrm{~W} / \mathrm{m}^{2}$, which is numerically simulated using SolTrace software and the instantaneous efficiency is $75.86 \%$ calculated by (1); secondly, outlet average temperature is $36.8^{\circ} \mathrm{C}$, which is numerically simulated using CFD software which is a popular tool in solar radiation and application fields [14-17], and the instantaneous efficiency is $63.87 \%$ calculated by (2). Figures 4 and 5 are the picture of heat density distribution and the temperature cloud picture of the receiver tube in cold climate region.

\subsection{Influence Factor Analysis of Instantaneous Efficiency.} There are many parameters which can affect the collector efficiency, so the analysis of the influence factors can provide theoretical support and technical reserves for promotion and application of solar energy heat utilization technology. The main parameters in this paper are as follows: diameter, pipe length, condensation area, solar radiation intensity, flow rate, inlet temperature, and ambient temperature. Special points from different influencing factors, 7 factors and 3 level orthogonal tables for the orthogonal experiment, choosing L18 $\left(3^{7}\right)$ orthogonal tables, the factors, and mathematical method have been used for the test arrangement scheme.
Finally, by calculating and analyzing the test results, levels graphs are shown in Table 2.

As shown in Table 2, it needs 18 experimental results to simulate for each condition and then calculate the instantaneous efficiency. The experimental program and the simulation results are shown in Tables 3 and 4, respectively.

According to the results of Table 4, calculating the average values of factors index of $k 1, k 2$, and $k 3$ and average maximal deviation $R$ at the same level and analyzing the primary and secondary factors, the results are shown in Table 5. It can be seen from the table that average maximal deviation $R$ represents the influence degree of instantaneous efficiency of collector, and the greater average maximal deviation stands for the greater influence degree. Therefore, the results show that the order of effect extent for average maximal deviation of each factor is inlet temperature, solar radiation intensity, diameter, flow rate, condensation area, pipe length, and ambient temperature. According to the results, the effects of the three main factors on instantaneous efficiency determined by single factor experiment are shown in Figures 6-8.

It can be seen from Figure 6 that with the increasing inlet temperature the efficiency of collector decreases and the decreasing extent is gradually strong. The reason is that the temperature of the metal and glass tube increases with the increasing inlet temperature, the temperature difference between metal wall and outside glass tube gradually increases, and the radiative heat loss increases. In another view, the temperature outside glass tube increases with increasing radiative heat loss between metal pipe and glass tube. Meanwhile the thermal radiation loss and convective heat loss outside the surface of the glass tube to the atmosphere have also an increase. It can be seen from the figure that the efficiency almost goes to more than $60 \%$ with the inlet temperature less than $150^{\circ} \mathrm{C}$. In Figure 7, the increasing of solar radiation intensity causes the instantaneous efficiency going higher with about $56.36 \sim 64.62 \%$. Also, it can be found that the trend becomes rapid in $200-600 \mathrm{~W} / \mathrm{m}^{2}$; however, it slows down after the solar radiation of $600 \mathrm{~W} / \mathrm{m}^{2}$.

Figure 8 shows that with the increasing diameter of collector tube the collector efficiency increases at the beginning period and becomes slow after the diameter reaches up to $75 \mathrm{~mm}$. Also, the efficiency decreases with increasing diameter when the diameter is more than $75 \mathrm{~mm}$. The main reason is that with the increasing diameter of the metal pipe the area of collector increases, and the absorbed solar energy increases accordingly, which results in the increasing efficiency. On the 

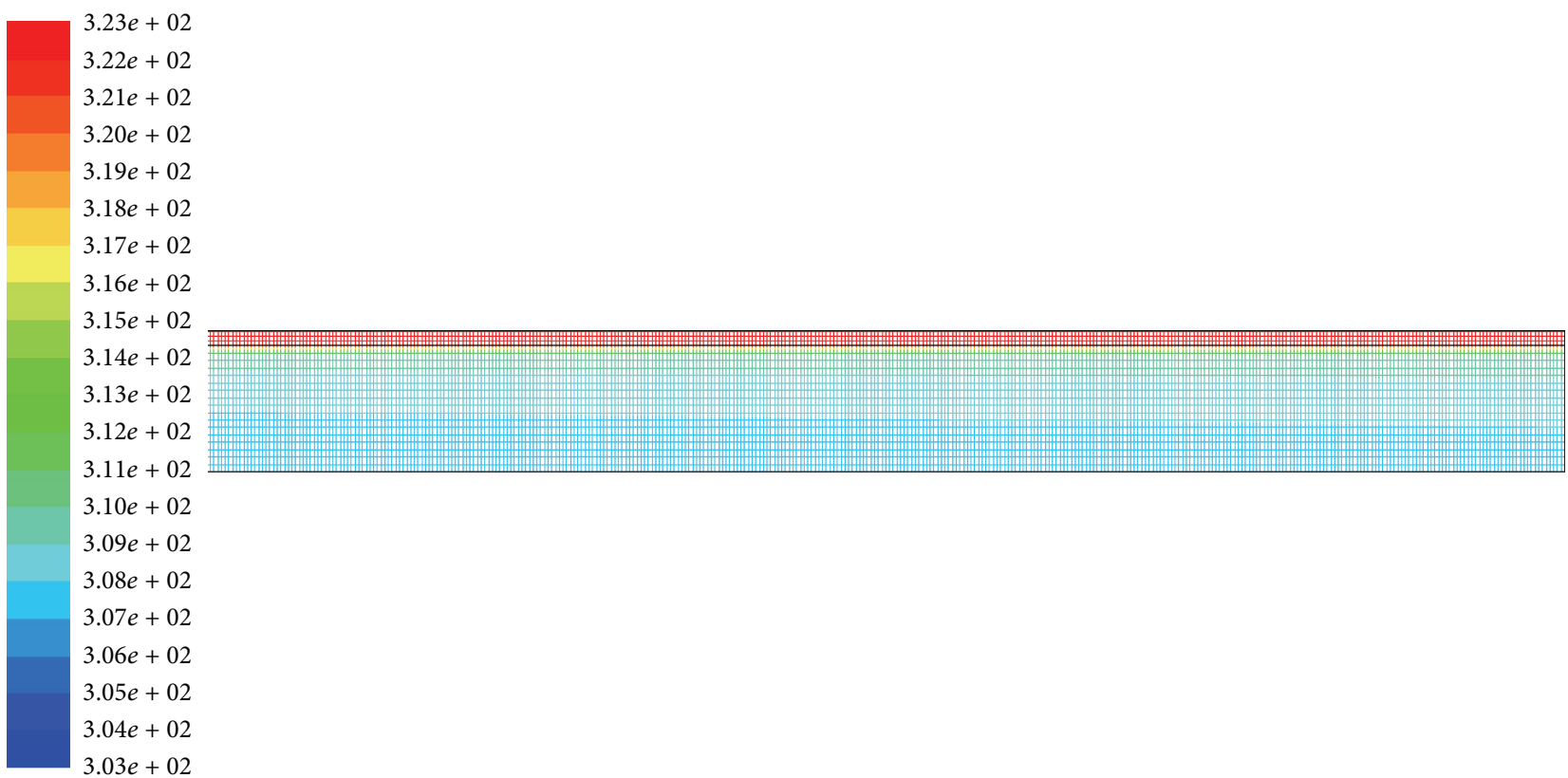

Figure 5: The temperature cloud of the receiver tube.

TABLE 3: Experimental program.

\begin{tabular}{lccccccc}
\hline Number & $\begin{array}{c}\text { Pipe length } \\
(\mathrm{m})\end{array}$ & $\begin{array}{c}\text { Condensation area } \\
(\mathrm{m})\end{array}$ & $\begin{array}{c}\text { Diameter } \\
(\mathrm{mm})\end{array}$ & $\begin{array}{c}\text { Solar radiation } \\
\text { intensity } \\
\left(\mathrm{W} / \mathrm{m}^{2}\right)\end{array}$ & $\begin{array}{c}\text { Ambient } \\
\text { temperature } \\
\left({ }^{\circ} \mathrm{C}\right)\end{array}$ & $\begin{array}{c}\text { Flow rate } \\
(\mathrm{m} / \mathrm{s})\end{array}$ & $\begin{array}{c}\text { Inlet temperature } \\
\left({ }^{\circ} \mathrm{C}\right)\end{array}$ \\
\hline 1 & 1 & 1 & 1 & 1 & 1 & 1 & 1 \\
2 & 1 & 2 & 2 & 2 & 2 & 2 & 2 \\
3 & 1 & 3 & 3 & 3 & 3 & 3 & 3 \\
4 & 2 & 1 & 1 & 2 & 2 & 3 & 3 \\
5 & 2 & 2 & 2 & 3 & 3 & 1 & 1 \\
6 & 2 & 3 & 3 & 1 & 1 & 2 & 2 \\
7 & 3 & 1 & 2 & 1 & 3 & 2 & 3 \\
8 & 3 & 2 & 3 & 2 & 1 & 3 & 1 \\
9 & 3 & 3 & 1 & 3 & 2 & 1 & 2 \\
10 & 1 & 1 & 3 & 3 & 2 & 2 & 1 \\
11 & 1 & 2 & 1 & 1 & 3 & 3 & 2 \\
12 & 1 & 3 & 2 & 2 & 1 & 1 & 3 \\
13 & 2 & 1 & 2 & 3 & 1 & 3 & 2 \\
14 & 2 & 2 & 3 & 1 & 2 & 1 & 3 \\
15 & 2 & 3 & 1 & 2 & 3 & 2 & 1 \\
16 & 3 & 1 & 3 & 2 & 3 & 1 & 2 \\
17 & 3 & 2 & 1 & 3 & 1 & 2 & 3 \\
18 & 3 & 3 & 2 & 1 & 2 & 3 & 1 \\
\hline
\end{tabular}

other hand, the efficiency of the collector decreases with heat loss increasing caused by increasing the surface area of the collector. In the meantime, with the increasing diameter of collector tube, the flow velocity obviously decreases because the flow rate is kept at a constant, and the efficiency must decrease because of the decreasing convective heat transfer rate between the inner wall of metal tube and the fluid. Based on the above analysis, there is a critical value of the diameter for this condition. When the diameter is less than the critical value, the efficiency increases with increasing the diameter, whereas it decreases with increasing the diameter when the diameter is more than the critical value. 
TABLE 4: The experimental results of instantaneous efficiency.

\begin{tabular}{lccccc}
\hline Serial number & $\begin{array}{c}\text { Instantaneous } \\
\text { efficiency (\%) }\end{array}$ & Serial number & $\begin{array}{c}\text { Instantaneous } \\
\text { efficiency }(\%)\end{array}$ & Serial number & $\begin{array}{c}\text { Instantaneous efficiency } \\
(\%)\end{array}$ \\
\hline 1 & 53.15 & 7 & 51.09 & 13 & 63.77 \\
2 & 63.65 & 8 & 60.93 & 14 & 45.26 \\
3 & 54.83 & 9 & 58.79 & 15 & 62.09 \\
4 & 54.04 & 10 & 64.20 & 16 & 53.15 \\
5 & 64.10 & 11 & 50.29 & 17 & 63.65 \\
6 & 59.02 & 12 & 52.18 & 18 & 54.83 \\
\hline
\end{tabular}

TABLE 5: Instantaneous efficiency factors analysis of parabolic trough collector (\%).

\begin{tabular}{lccccccc}
\hline & Pipe length & Condensation area & Diameter & $\begin{array}{c}\text { Solar radiation } \\
\text { intensity }\end{array}$ & $\begin{array}{c}\text { Ambient } \\
\text { temperature }\end{array}$ & Flow rate & Inlet temperature \\
\hline$k 1$ & 56.38 & 58.38 & 55.38 & 52.51 & 57.17 & 56.25 & 60.12 \\
$k 2$ & 58.05 & 56.36 & 58.50 & 59.49 & 57.03 & 59.00 & 59.93 \\
$k 3$ & 57.50 & 57.19 & 58.05 & 59.94 & 57.74 & 56.68 & 51.89 \\
$R$ & 1.664 & 2.020 & 3.120 & 7.431 & 0.712 & 2.745 & 8.227 \\
\hline
\end{tabular}

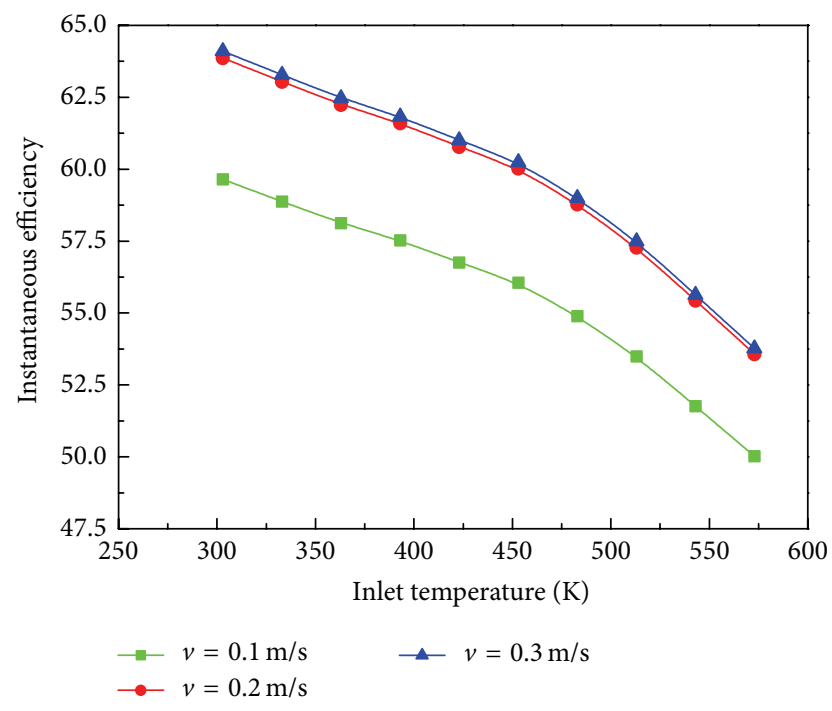

FIGURE 6: The influence of inlet temperature on the instantaneous efficiency.

\section{Conclusions}

Taking climatic performance into account, effects of different factors on instantaneous efficiency have been determined by orthogonal experiment and single factor experiment. The main conclusions are as follows:

(1) The results show that the order of effect extent for average maximal deviation of each factor is inlet temperature, solar radiation intensity, diameter, flow rate, condensation area, pipe length, and ambient temperature.

(2) The inlet temperature is the uppermost factor. The efficiency of collector is lower and lower, and the

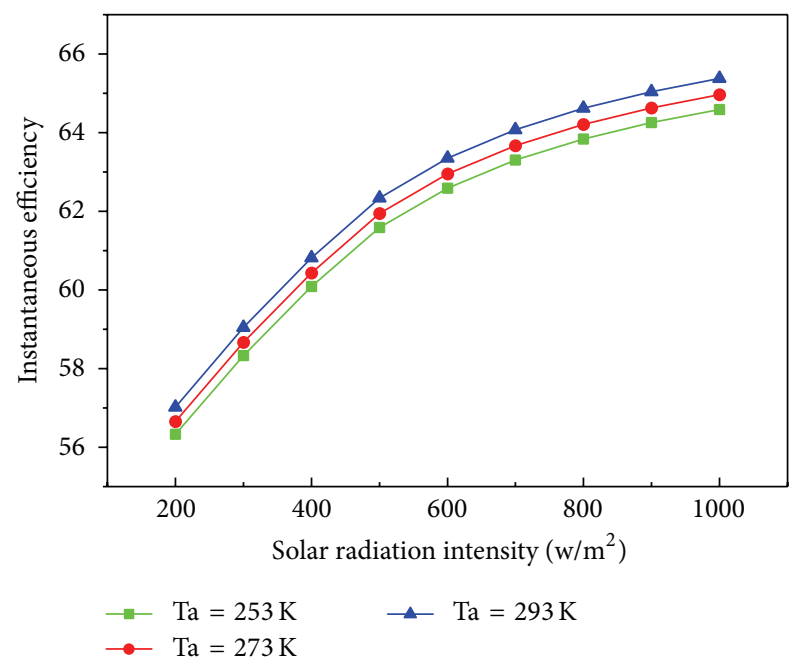

FIGURE 7: The influence of solar radiation intensity on the instantaneous efficiency.

decrease extent is gradually strong with the increasing inlet temperature.

(3) The ambient temperature has a minimum effect on the efficiency. The instantaneous efficiency of collector has a slight increasing of about $1 \%$ when the ambient temperature increases.

(4) In this model, there is an optimal outer diameter of $75 \mathrm{~mm}$ for the collector. Also, the instantaneous efficiency of collector has a maximum in this case.

The results can provide a reference for the exploitation and utilization of this collector in cold climate region. 


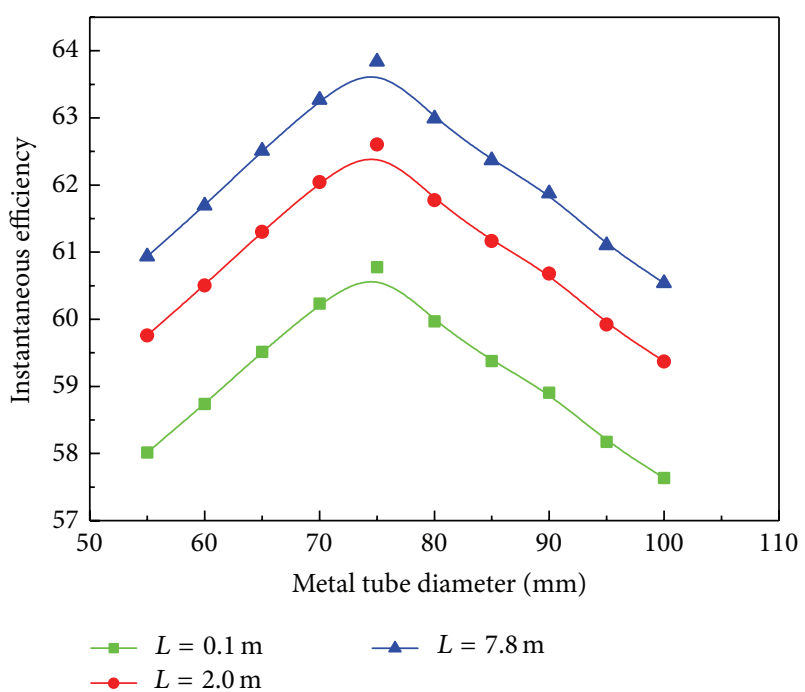

FIGURE 8: The influence of metal tube diameter on the instantaneous efficiency.

\section{Conflict of Interests}

The authors declare that there is no conflict of interests regarding the publication of this paper.

\section{Acknowledgments}

This work is supported by the National Natural Science Foundation of China (nos. 51176024 and 51406033) and University Nursing Program for Young Scholars with Creative Talents in Heilongjiang Province (no. UNPYSCT-2015075). Besides, a very special acknowledgement is made to the editors and referees who made important comments to improve this paper.

\section{References}

[1] N. Nallusamy, S. Sampath, and R. Velraj, "Experimental investigation on a combined sensible and latent heat storage system integrated with constant/varying (solar) heat sources," Renewable Energy, vol. 32, no. 7, pp. 1206-1227, 2007.

[2] D. Mills, "Advances in solar thermal electricity technology," Solar Energy, vol. 76, no. 1-3, pp. 19-31, 2004.

[3] M. Thirugnanasambandam, S. Iniyan, and R. Goic, "A review of solar thermal technologies," Renewable and Sustainable Energy Reviews, vol. 14, no. 1, pp. 312-322, 2010.

[4] H. Price, E. Lüpfert, D. Kearney et al., "Advances in parabolic trough solar power technology," Journal of Solar Energy Engineering, Transactions of the ASME, vol. 124, no. 2, pp. 109-125, 2002.

[5] Z.-C. Gao, J. Sui, Q.-B. Liu et al., "Simulation on the performance of a $30 \mathrm{~m} 2$ parabolic trough collector," Journal of Engineering Thermophysics, vol. 31, no. 4, pp. 541-544, 2010 (Chinese).

[6] Q. Liu, Y. Wang, Z. Gao, J. Sui, H. Jin, and H. Li, "Experimental investigation on a parabolic trough solar collector for thermal power generation," Science China Technological Sciences, vol. 53, no. 1, pp. 52-56, 2010.
[7] E. Lüpfert, K.-J. Riffelmann, H. Price, F. Burkholder, and T. Moss, "Experimental analysis of overall thermal properties of parabolic trough receivers," Journal of Solar Energy Engineering, Transactions of the ASME, vol. 130, no. 2, Article ID 021007, 5 pages, 2008.

[8] L. Zhang, Z. Yu, L. Fan et al., "An experimental investigation of the heat losses of a U-type solar heat pipe receiver of a parabolic trough collector-based natural circulation steam generation system," Renewable Energy, vol. 57, pp. 262-268, 2013.

[9] L. Zhang, W. Wang, Z. Yu et al., "An experimental investigation of a natural circulation heat pipe system applied to a parabolic trough solar collector steam generation system," Solar Energy, vol. 86, no. 3, pp. 911-919, 2012.

[10] S. A. Kalogirou, "Solar thermal collectors and applications," Progress in Energy and Combustion Science, vol. 30, no. 3, pp. 231-295, 2004.

[11] J. Xiao, Y.-L. He, Z.-D. Cheng, Y.-B. Tao, and R.-J. Xu, "Performance analysis of parabolic trough solar collector," Journal of Engineering Thermophysics, vol. 30, no. 5, pp. 729-733, 2009 (Chinese).

[12] N. Naeeni and M. Yaghoubi, "Analysis of wind flow around a parabolic collector (1) fluid flow," Renewable Energy, vol. 32, no. 11, pp. 1898-1916, 2007.

[13] V. Dudley, G. Kolb, M. Sloan et al., "SEGS LS2 solar collectortest results," Tech. Rep. SANDIA94-1884, Sandia National Laboratories, Albuquerque, NM, USA, 1994.

[14] F. Wang, Y. Shuai, H. Tan, and C. Yu, "Thermal performance analysis of porous media receiver with concentrated solar irradiation," International Journal of Heat and Mass Transfer, vol. 62, no. 1, pp. 247-254, 2013.

[15] F. Wang, J. Tan, and Z. Wang, "Heat transfer analysis of porous media receiver with different transport and thermophysical models using mixture as feeding gas," Energy Conversion and Management, vol. 83, pp. 159-166, 2014.

[16] Q. Mao, Y. Yuan, and Y. Shuai, "Effects of atmospheric aerosol on the direct normal irradiance on the earth's surface," International Journal of Hydrogen Energy, vol. 39, no. 12, pp. 6364-6370, 2014.

[17] Q. Mao, Y. Shuai, and Y. Yuan, "Study on radiation flux of the receiver with a parabolic solar concentrator system," Energy Conversion and Management, vol. 84, pp. 1-6, 2014. 

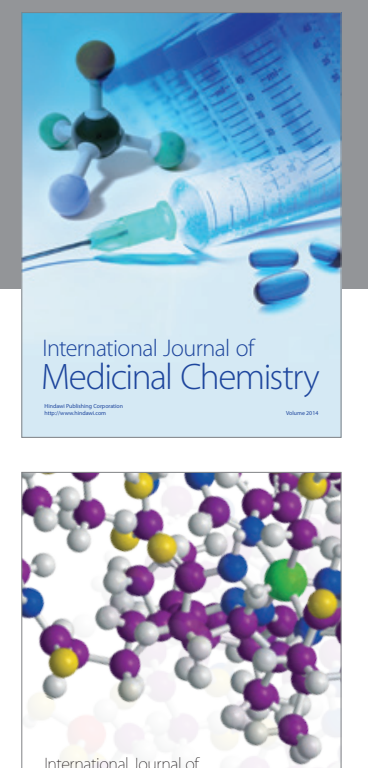

\section{Carbohydrate} Chemistry

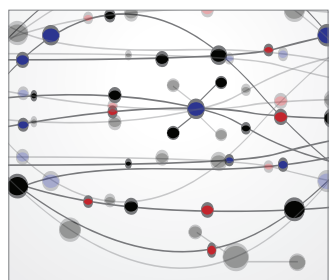

The Scientific World Journal
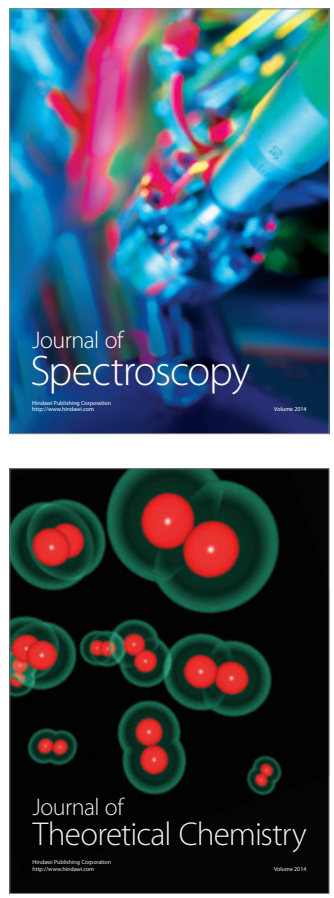
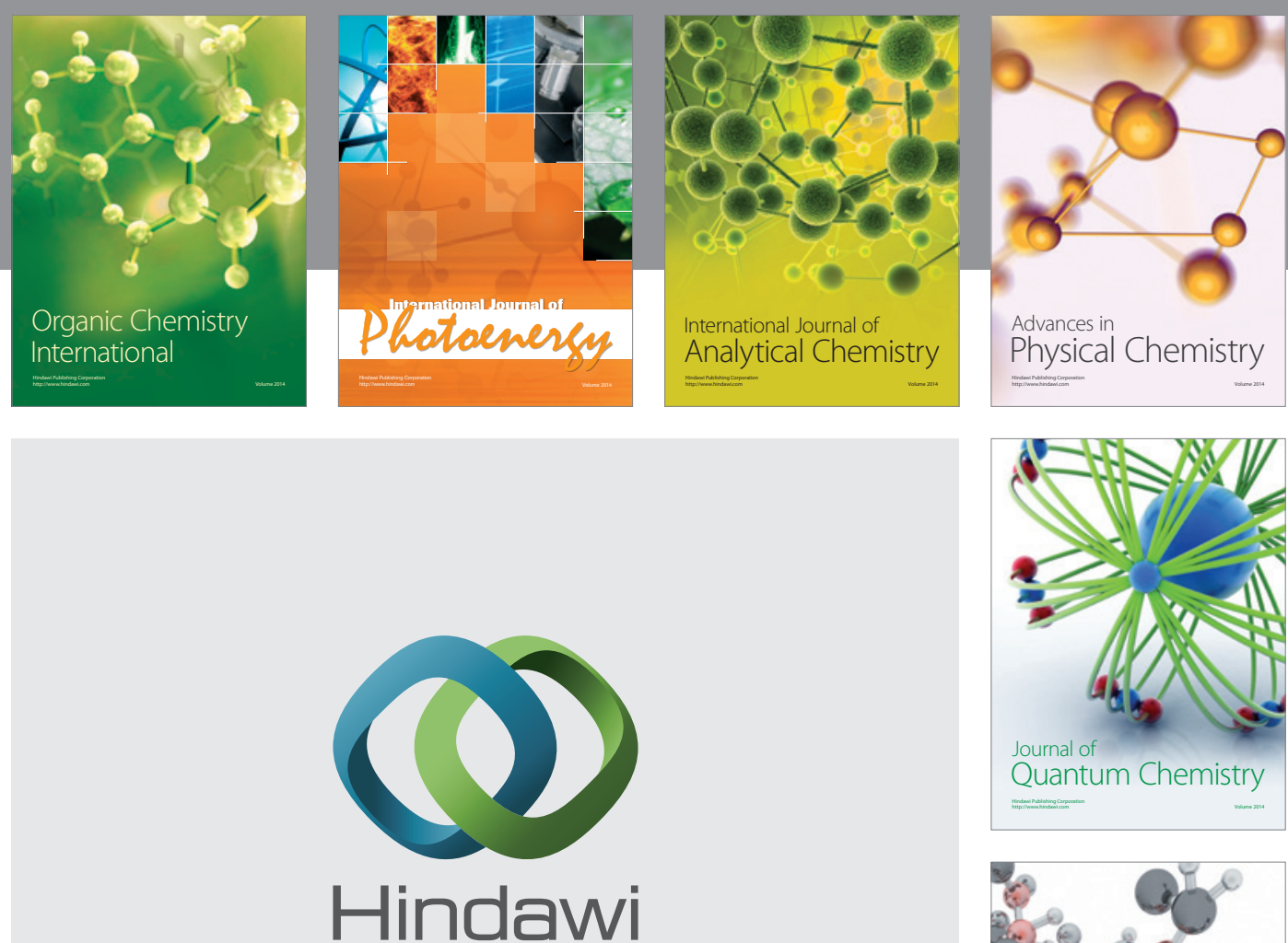

Submit your manuscripts at

http://www.hindawi.com

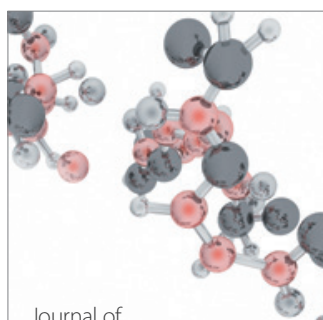

Analytical Methods

in Chemistry

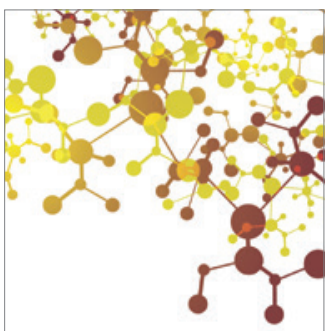

Journal of

Applied Chemistry

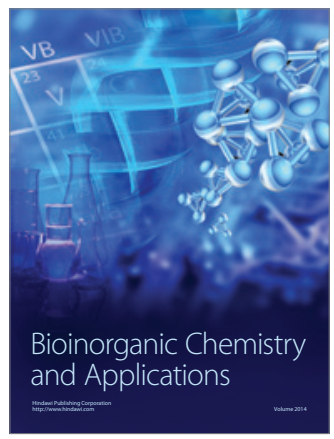

Inorganic Chemistry
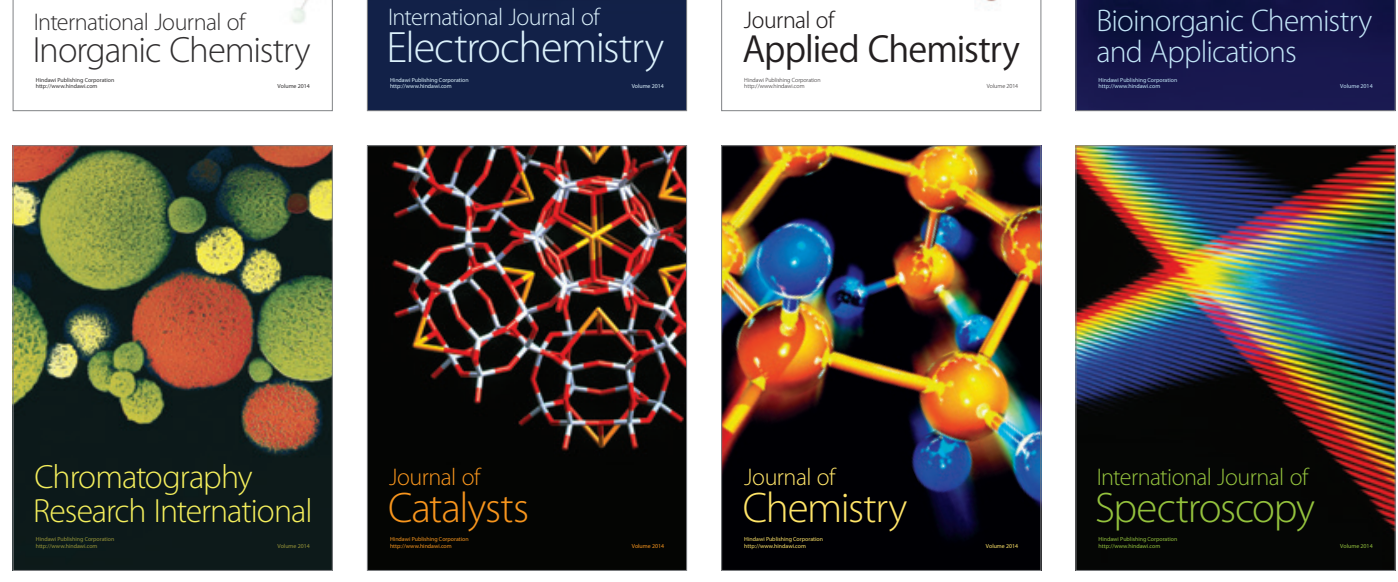